\title{
GEOENGINEERING: WORTHY OF CAUTIOUS EVALUATION?
}

\author{
An Editorial Comment
}

If the increasing concentrations of greenhouse gases due to human activities are indeed causing inadvertent change in the climate, then can we not counter these influences by advertent changes of some type, deliberately geoengineering the climate to ensure optimal conditions? This is a question that was first considered several decades ago, soon after acceptance of indications that it was indeed likely that human activities could affect the global climate (e.g., Marchetti, 1975; NAS, 1992). Scientific evidence now clearly indicates that human activities have initiated significant climatic change and that much greater change lies ahead (IPCC, 2001a), that the impacts of these changes will cause significant consequences for the environment and society (IPCC, 2001b), and that switching the global energy system away from its heavy dependence on fossil fuels is likely to require more than a century (IPCC, 2001c).

With the Kyoto Protocol proving to be a difficult first step to slowing the rate of growth in emissions and with slow progress on moving to second and third steps that would actually start to reduce emissions, Crutzen (2006) argues that it may be time to think much more seriously about geoengineering the Earth's climate. In addition to undertaking geoengineering to avoid the "dangerous anthropogenic interference with the climate system," which the international community of nations agreed in 1992 was their objective in the UN Framework Convention on Climate Change, Crutzen proposes to offset the warming influence of removing the loading of tropospheric aerosols so as to alleviate their deleterious health effects, which is an interesting new aspect meriting consideration. In addition to the many scientific, legal, ethical, and societal issues that he raises with respect to undertaking such efforts, this note offers a few additional thoughts and comments.

\section{On the Range of Possibilities}

Crutzen's proposal to, in essence, create a human volcano by injecting sulfate aerosols into the stratosphere is only one of a wide range of geoengineering possibilities (e.g., see MacCracken, 1991; Leemans et al., 1995; Flannery et al., 1997). Starting furthest from the surface of the Earth ${ }^{1}$, Early (1989) proposed to place a solar deflector at the first Sun-Earth Lagrange point (1.5 million kilometers toward the Sun, where the gravitational pull of the two bodies would be about equal). With a diameter of $2000 \mathrm{~km}$, the deflector would reduce incoming solar radiation by about $1 \%$, which would be about enough to offset the additional forcing expected 
from $\mathrm{CO}_{2}$ emissions during the 21 st century. Reducing solar radiation by this small amount would not be expected to have significant environmental consequences. However, pursuing this approach most cost effectively would require setting up a manufacturing plant on the Moon, which would entail substantial upfront costs. ${ }^{2}$ While one could conceivably control the rate of onset of the effect by angling the deflector and easily stop the effect if adverse environmental consequences arose, one would essentially have to fully commit the resources needed for this approach before there could be any effect (or even testing) of the approach. Thus, the upfront costs would be high and so directly comparable to the difference in costs that now exist between fossil fuel and renewable or other energy sources, likely demonstrating that improvements in energy technologies would be a less expensive and less risky path.

Solar shielding could also be placed in near-Earth orbit. Offsetting roughly $1 \%$ of incoming solar radiation would require about 55,000 orbiting solar sails (e.g., spread out Mylar sheets), each roughly $10 \mathrm{~km}$ by $10 \mathrm{~km}$ in size (NRC, 1992). While this approach could be undertaken incrementally, the control problem would be overwhelming, not to mention that in passing between the Sun and Earth's surface, they would cause sunlight to flicker.

Placing reflectors in the stratosphere, as Crutzen is proposing, has the advantage that if this is done using small particles, then, once injected, the particles will remain aloft for up to a few years. As he notes, this approach can be tried in an incremental manner and halting further injection would quite quickly end the experiment if the consequences were not as projected. One important disadvantage of sulfate aerosol particles is that they scatter about ten times as much radiation as they reflect, whitening the skies and creating beautiful sunrises and sunsets while seriously diminishing the direct solar beam, thereby reducing the effectiveness of the generation of energy using direct-solar beam approaches such as the solar power tower. ${ }^{3}$ Volcanic aerosols can also exacerbate loss of ozone, and with the increasing concentration of $\mathrm{CO}_{2}$ tending to cool the lower stratosphere, having a permanent loading of additional aerosols might well cause significant depletion in polar regions.

It was to avoid the problem of scattering that Teller et al. (1997) proposed injecting very small corner reflectors, which would reflect the solar radiation toward its source rather than scattering so much radiation. Possible complications of effects of a layer of such particles were not considered (e.g., interference with communication signals), and having the corner reflectors sized to optimally reflect UV radiation would actually have relatively little effect on the amount of energy reaching the surface-troposphere system (and thus on the climate), although it might well affect tropospheric chemistry and the chemical cleansing capacity of the atmosphere. Crutzen alternatively suggests use of soot instead of sulfates to reduce scattering, and, in an interesting synergy, goes on to add that the resulting warming could help to offset $\mathrm{CO}_{2}$-induced cooling and the consequent reduction in ozone. 
As Crutzen makes clear, we are already affecting the climate as a result of the tropospheric sulfate loading that results primarily from $\mathrm{SO}_{2}$ emissions as a result of coal combustion. In that the lifetime of sulfate in the atmosphere is roughly a week, the longer lifetimes with stratospheric injection can reduce the required loading by a factor of roughly 100, depending on how cloud modification effects are counted. Tropospheric geoengineering is not only problematic because it requires much more material, but also because the relatively short lifetime of sulfate aerosols would necessitate multiple source regions to achieve roughly even coverage. Such coverage is likely important because the present experience with tropospheric aerosols is that they are concentrated regionally, and that at least some of their climatic effects are regional rather than global (although their influence may be extended globally through alteration of atmospheric circulation). Because Crutzen's injections would be spread globally, the temperature response in comparison to the tropospheric aerosols that would be reduced would seem likely to lead to warming in the Northern Hemisphere and cooling in the Southern Hemisphere, a response that might be accounted for by varying the stratospheric injections by latitude and season.

Approaches to countering greenhouse gas induced warming by increasing surface reflectivity to counter global warming are even more problematic. Not only is the amount of solar radiation that reaches the surface reduced by about $50 \%$ compared to the top of the atmosphere, but the amount of available land with a low albedo is also limited. To overcome this problem, Gaskill and Reece (2003) proposed increasing the reflectivity of large desert areas. Although this would lead to a more modest increase in the albedo per unit area, they would, if the weather remains unchanged, benefit from having the clear skies, although modification of the surface albedo might well induce regional climatic consequences, and these might lead to impacts that are more serious than the amount of climate change that is being offset. As another alternative, changing the albedo of the ocean could lead to a very large change in surface reflectivity, but would require floating a reflector that would ultimately need to grow to roughly the size of a continent; such a modification would likely induce its own weather, perhaps reducing the overall effectiveness of the approach.

Given, therefore, the varying tradeoffs between up-front costs, effectiveness, and adverse environmental consequences, it may well be that, as Crutzen's approach proposes, modification of the stratosphere is thus optimal in a scientific sense. Finding a means of minimizing the scattering of radiation and ozone depletion merits serious attention, however, and determining how to achieve the most appropriate latitudinal, seasonal, and regional variations in the response will be important.

\section{Criteria for Evaluating Geoengineering Proposals}

Crutzen focuses on comparing the costs of geoengineering versus not doing so. Additionally, the costs of such geoengineering efforts should be compared to the 
costs of switching from fossil fuel sources of energy to non-fossil fuel sources and efficiency improvements (e.g., see NAS, 1992). It is also important to recognize that the higher $\mathrm{CO}_{2}$ concentration that would likely be the consequence of offsetting some of the warming would itself lead to important impacts, including, as a negative, acidification of the ocean, and, as a positive, enhanced water use efficiency of some crops. That many analyses comparing fossil versus renewable sources of energy are so limited in their analyses of the consequences of the changes in $\mathrm{CO}_{2}$ and climate makes clear that these comparisons will not be straightforward.

In addition, assuming that a viable and cost-effective stratospheric injection approach can be found [and NAS (1992) also considers numerous high-altitude balloons as a means of reflecting the required amount of solar radiation], it is important to realize that, to be effective, the commitment to this approach must match the lifetime of the $\mathrm{CO}_{2}$ increment that is supposedly being offset. To first order, this means that each year's emission of $\mathrm{CO}_{2}$ would need to be offset by roughly a 200-year commitment to the stratospheric injection strategy, because whatever is injected (i.e., particles or reflecting balloons) is likely to be removed in a year or two (note that for many halocarbon emissions, the commitment to the offset must be thousands of years, whereas for methane emissions it would need to only be for a few decades). Were the geoengineering effort to stop, the radiative forcing of the $\mathrm{CO}_{2}$ would no longer be offset and warming would resume.

Thus, if greenhouse gas emissions are not going to be reduced, there will not only need to be an increasingly aggressive geoengineering effort to counter-balance the radiative influences, but the effort also would need to be continued virtually indefinitely. Although it might be conceivable for one nation to actually commit to such a program, it seems rather unlikely that a global coalition of nations could be kept together to sustain such a diversion of resources for a task that would seem, to the typical citizen, to generate no immediate or direct benefits (e.g., generation of energy, as might result from development of solar power satellites were a satellite approach favored).

In addition to the political, ethical, and economic issues that such a long-term commitment would raise, there is also a potential legal impediment. Reacting to the attempts at weather modification during the Vietnam War, the nations of the world agreed in 1978 to the UN Convention on the Prohibition of Military or any Other Hostile Use of Environmental Modification Techniques ${ }^{4}$ (Fleming, 2004), which essentially prohibits weather modification that any nation would consider hostile or environmentally damaging. In that "climate" is really a mathematical construct created by averaging over the weather, it would not be far-fetched to argue that this treaty might well not permit geoengineering schemes to be used for the purpose of climate change, or counterbalancing it (indeed, changing climate patterns is specifically mentioned as being covered in one of the understandings of the treaty). The notion of one or a few countries proceeding on some geoengineering approach without the permission of all countries would almost certainly be considered hostile 
by some nation. Given this situation and perspective, investing in research, needed as it may be, might be seen as premature. Thus, at the very least, a treaty modification might be needed to get permission to move forward (and thus of how much change would be undertaken and who would decide optimal conditions, etc.).

There has already been some experience with political consideration of geoengineering, and in this case additional considerations arose. In its initial formulation in mid 2001, President Bush's Climate Change Technology Initiative included consideration of geoengineering as one of the possible approaches, and indeed a meeting was held in the fall of 2001 and a draft report prepared (Ehsan Khan, personal communication). A powerful argument against proceeding emerged, namely that if a viable and low cost geoengineering alternative really were available, economic analysis would then seem to argue against continuing to try to reduce $\mathrm{CO}_{2}$ emissions. As such, geoengineering would really be, in essence, an enabler for undiminished addiction to fossil fuels, roughly equivalent to foregoing fire insurance based on an assurance that the fire department was right next door and could quickly put out any blaze. In addition to adding to the perception that the Administration's emission reduction program was not serious, relying on geoengineering came across as only conceivable if one had an unrealistically complete understanding of all the possible situations that could lie ahead (i.e., could be absolutely assured it would work in all cases for an indefinite time). Without such knowledge, particularly regarding the potential for surprises and abrupt change, full reliance on geoengineering to counterbalance the climate-changing effects of greenhouse gases would, over time, not only compound the necessity of sustaining the geoengineering option, but also mean that stopping might well result in even greater consequences than if one had not pursued the geoengineering approach at all, especially in comparison to devoting the resources to reducing the costs of non-fossil energy technologies.

This perspective changed the nature of the argument for geoengineering research to doing so only as a backstop strategy for dealing with unexpectedly rapid or damaging impacts (Ehsan Khan, personal communication). Crutzen, in his paper, seems to be arguing we are nearing or have reached the point where dangerous consequences seem likely to result, and so argues for moving ahead with research and even testing on that basis as well. Given how little energy technology research on this issue that the US and international communities are currently undertaking (e.g., the US effort of roughly $\$ 3 B$ per year amounts to about 3 cents per US citizen per day - hardly a significant amount), it would seem we are a good ways from exhausting our options. While research to consider geoengineering as a backstop approach may well be merited (although likely much more appropriate if all other steps are also being taken than if they are not), the risks and the necessary longterm commitment involved would seem to favor making an even stronger case for recognizing the seriousness of the climate change issue and encouraging a much more aggressive energy research and emissions control effort by the US and other nations (e.g., see Hoffert et al., 2002). 


\section{On the Scientific Basis for Proceeding}

The scientific basis for geoengineering approaches also requires much closer investigation. Crutzen continues to rely on an indication first made over two decades ago that forcings with different latitudinal and seasonal patterns will nonetheless have the same latitudinal and seasonal response of surface temperature. Specifically, Crutzen cites the results of Govindasamy and Caldiera (2000), whose model results indicate that, at least for the surface temperature response, roughly a $1.8 \%$ decrease in the solar constant would quite closely balance a doubling of the $\mathrm{CO}_{2}$ concentration, even though there are significant differences in the seasonal and spatial patterns of forcing. Indeed, this assumption is implicit in the comparisons of forcing made by the IPCC; for example, see Figure 3 on page 8 of IPCC (2001a), where forcings due to sulfate and other aerosols, tropospheric ozone, contrails, and land cover change, each with their particular pattern, are compared without adjustment to global forcing by greenhouse gases.

That this may well not be the case would seem to be demonstrated by the correlation of the waxing and waning of ice ages with orbital element cycles. Essentially all that the orbital element changes do in terms of radiative forcing is to alter the seasonal and latitudinal patterns; they do not significantly change the integrated annual solar flux to the Earth system (attempts to account for this by considering the radiative influence of the ice sheets as a forcing, for example, seem to be confusing a forcing with a feedback). As a result, orbital forcing would be assigned a near zero value on the IPCC diagram, and yet these orbital variations appear to be the drivers of the ice age cycling that the Earth has experienced over the past million years. Indeed, looking closely at IPCC's findings, it is recognized that the response to the greater loading of sulfate in the Northern than in the Southern Hemisphere has led to a larger temperature response in the Northern Hemisphere. In a manner similar to the consequences that result from a regional modification of sea surface temperature during an El Niño, it would seem quite plausible that the regional sulfate distribution is also having effects on atmospheric circulation that spread out around the hemisphere in a complex way from where the sulfate is concentrated.

Before proposing that geoengineering might be able to really counterbalance the temperature response from increasing greenhouse gas and aerosol concentrations, a much clearer explanation is thus needed about the long-term effects on climate of differences in the latitudinal and seasonal patterns of the forcing, and how changes in the oceans and in snow and ice cover might affect the response. In addition, the differences between the tropospheric sulfate-induced climatic effects that Crutzen is proposing to replace with stratospheric aerosol effects need to be understood; there is already some indication that volcanic aerosols can, by altering the atmospheric circulation, produce winter warming over Northern Hemispheric continents (e.g., see Robock, 2002), so simple counter-balancing may not be the actual consequence of stratospheric injections. 


\section{On Focusing on Counter-Acting Specific Impacts}

Finally, I would just note that in considering geoengineering options, it may well be better to focus attention on trying to counter-balance specific consequences of global warming than on counter-balancing global warming itself (see Leemans et al., 2001). For example, Johnson (1997) argues that, in the face of possible changes in ocean conditions, damming the Strait of Gibraltar might be useful in keeping Europe and the North Atlantic region warm by cutting off the cooling influence of the increasing salinity of the Mediterranean. Other authors argue that damming the Bering Strait or Siberian rivers flowing into the Arctic might be useful in controlling what happens in the Arctic Ocean (e.g., see Weart, 2004). Such proposals and possibilities may also merit consideration as options.

Somewhat more speculatively, I have suggested (in the draft DOE workshop report prepared by Khan, personal communication) that injecting a relatively large amount of aerosols into the Arctic lower stratosphere, where the aerosols might persist for only 6 months and so not impact winter ozone levels, might be used to reduce the solar radiation enough that it would promote an earlier icing up of the Arctic Ocean that would in turn induce further cooling because of the higher albedo of sea ice. Were this to occur, it might be possible that a one-summer injection might promote Arctic cooling that would persist for a few years, thereby limiting Arctic warming and its extension to lower latitudes and helping to maintain the unique ecosystems dependent on near shore sea ice (i.e., polar bears, seals, etc.). In addition, the injected Arctic aerosol might help to screen mountain glaciers and the Greenland Ice Sheet, slowing their loss and thereby benefitting the global community by slowing sea level rise (and maybe also by helping to sustain the Meridional Overturning Circulation).

\section{Concluding Thought}

What is clear from review of the various options is that it is easier to warm the climate than to cool it. For this reason, continued and increasing emissions of greenhouse gases merit very serious control efforts. In addition, however, as Crutzen suggests, research would be a prudent option, both on the globally uniform approach to geoengineering proposed by Crutzen and, in my view, on dealing with specific changes, some of which have already begun, in a way that might benefit the world community of nations.

\section{Notes}

\footnotetext{
${ }^{1}$ In this note I will focus only on those approaches of geoengineering involving proposals to counterbalance the warming effects of an increasing carbon dioxide concentration and not on approaches based on reducing the amount of $\mathrm{CO}_{2}$ in the atmosphere.
} 
${ }^{2}$ Were this or some other approach relating to addressing the Earth's climate-energy dilemma the focus of the US space exploration effort, perhaps the Administration's commitment to this expense would be seen as providing a substantive benefit for those on Earth paying for these adventures.

${ }^{3}$ Following the El Chichón eruption in 1982, measurements at the Barstow prototype solar power tower installation, which was roughly in the same latitudinal band as the early volcanic cloud, indicated that total solar radiation dropped about $2 \%$ whereas direct radiation (and therefore power production) dropped about $25 \%$. Once the volcanic aerosol loading decreased, the system worked as designed.

4 The text of the treaty can be downloaded from http://www1.umn.edu/humanrts/peace/docs/ conenvironmodification.html

\section{References}

Crutzen, P. J.: 2006, 'Albedo enhancement by stratospheric sulfate injections: A contribution to resolve a policy dilemma?', Climatic Change, this issue, DOI: 10.1007/s10584-006-9101-y.

Early, J. T.: 1989, 'Space-based solar screen to offset the greenhouse effect', J. Brit. Interplanetary Soc. 42, 567-569.

Flannery, B. P., Marland, G., Broecker, W., Ishatani, H., Keshgi, H., Komiyama, H., MacCracken, M., Rosenberg, N., Steinberg, M., and Wigley, T.: 1997, 'Geoengineering climate', in Robert G. Watts (ed.), The Engineering Response to Climate Change, pp. 379-427 (Chapter 8). Lewis Publishers, Boca Raton, 492 pp.

Fleming, J. R.: 2004, 'Fixing the weather and climate: Military and civilian schemes for cloud seeding and climate engineering', in Rosner, L. (ed.), The Technological Fix: How People Use Technology to Create and Solve Problems. Routledge, New York, Chapter 9, pp. 175-200.

Gaskill, A. Jr. and Reese, C. E.: 2003, 'Global warming mitigation by reduction of outgoing longwave radiation through large-scale surface albedo enhancement of deserts using white plastic polyethylene film-the global albedo enhancement project (GAEP) research plan', Report from Environmental Reference Materials, Inc., Research Triangle Park, NC, 90 pp.

Govindasamy, B. and Caldiera, K.: 2000, 'Geoengineering Earth's radiative balance to mitigate $\mathrm{CO}_{2}$ induced climatic change', Geophys. Res. Lett. 27, 2141-2144.

Hoffert, M. I., et al.: 2002, 'Advanced technology paths to global climate stability: Energy for a greenhouse planet', Science 298, 981-987.

Intergovernmental Panel on Climate Change (IPCC): 2001a, in Houghton, J. et al. (eds.), Climate Change 2001: Synthesis Report; Climate Change 2001: The Scientific Basis, Cambridge Univ. Press, 881 pp. (available at http://www.grida.no/climate/ipcc_tar/wg1/index.htm).

Intergovernmental Panel on Climate Change (IPCC): 2001b, in McCarthy, J. et al. (eds.), Climate Change 2001: Impacts, Adaptation and Vulnerability, Cambridge Univ. Press, 1032 pp. (available at http://www.grida.no/climate/ipcc_tar/wg2/).

Intergovernmental Panel on Climate Change (IPCC): 2001c, in Metz, B. et al. (eds.), it Climate Change 2001: Mitigation, Cambridge Univ. Press, 752 pp. (available at http://www.grida.no/climate/ ipcc_tar/wg3/index.htm).

Johnson, R. G.: 1997, 'Climate control requires a dam at the Strait of Gibraltar', EOS 78, 277, 280-281.

Leemans, R., Agrawala, S., Edmonds, J. A., MacCracken, M. C., Moss, R., and Ramakrishnan, P. S.: 1995, 'Mitigation: Cross-sectoral and other issues', in IPCC Working Group II Second Assessment Report, Cambridge University Press, Cambridge, Chapter 25, pp. 799-819.

MacCracken, M. C.: 1991, Geoengineering the Climate, Lawrence Livermore National Laboratory Report UCRL-JC-108014, Livermore CA.

Marchetti, C.: 1977, 'On geoengineering the $\mathrm{CO}_{2}$ problem', Climatic Change 1, 59-68.

National Academy of Sciences (NAS): 1992, Policy Implications of Greenhouse Warming: Mitigation, Adaptation, and the Science Base, National Academy Press, Washington DC. 
Robock, A.: 2002, 'The climatic aftermath', Science 295, 1242-1244.

Teller, E., Wood, L., and Hyde, R.: 1997, Global Warming and Ice Ages: I.Prospectsfor Physics-Based Modulation of Global Change, UCRL-JC-128715, Lawrence Livermore National Laboratory, Livermore CA.

Weart, S.: 2004, 'Climate modification schemes', in The Discovery of Global Warming, http://www.physicists.net/history/climate/RainMake.htm. 